Article

\title{
Prioritization of Local Indicators for the Development of an Age-Friendly City: A Community Perspective
}

\author{
Atiq Uz Zaman ${ }^{1, *(1)}$ and Katharine Thornton ${ }^{2}$ \\ 1 School of Design and the Built Environment, Curtin University, Perth, WA 6102, Australia \\ 2 Centre for Urban Transitions, Swinburne University of Technology, Melbourne, VIC 3122, Australia; \\ kjthornton@swin.edu.au \\ * Correspondence: atiq.zaman@curtin.edu.au; Tel.: +61-08-9266-9018
}

Received: 17 April 2018; Accepted: 17 June 2018; Published: 21 June 2018

\begin{abstract}
Due to the rapid transition of growing ageing populations around the world, there is an urgency to change in attitudes, policies and practices at all levels of governance to fulfil the potential of ageing in the 21st century. The World Health Organization (WHO) proposed an age-friendly checklist as a guideline for urban cities. However, the WHO's age-friendly indicators are generalized and overarching, and need modification by considering local needs. Therefore, localizing age-friendly indicators based on local priority is the first step in implementing a global age-friendly city agenda. This study aims to identify the priority indicators for age-friendly development at local government level in South Australia. The study considers the City of Unley, a local government organization in South Australia, as a case study. The study conducts a community perception survey to identify the important indicators, followed by a focus group consultation to identify the priority indicators based on local settings. The study identifies 25 indicators as priority indicators for the City of Unley that need to be considered for the development of age-friendly Unley. In addition, the study proposes several demonstration project ideas for local government to initiate participatory age-friendly projects for the local community. The findings of the study are important in assisting local government to develop age-friendly strategies by considering their local priority and achieving the global sustainability agenda.
\end{abstract}

Keywords: local priority; indicators; age-friendly city; Unley City Council; South Australia

\section{Introduction}

We are witnessing an unprecedented global demographic transition of a rapidly growing ageing population around the world. By 2050, older people (defined as aged 60 or over) will make up more than one-fifth of the global population [1]. Australia ranks second highest among the countries of the world whose population is likely to live for another 25 years after they turn 60 [2]. The life expectancy on average across OECD (the Organization for Economic Co-operation and Development) countries has increased 10 years since 1970 from 70 years to over 80 years in 2011 [3]. Demographers identify older people in our population in two categories: the "young-old" (65-74 years) and the "old-old" (75 years and over). The number of "old-old" people in OECD countries is significantly high. For example, in 2012 more than $30 \%$ of the population comprised of older people in Japan and it is predicted that by the middle of the century, many countries will have a similar proportion of older people to that of Japan in 2012 [4].

The current trends of the ageing population indicate an increase in the "old-old" segment which has significant effects on our existing health and social policies [5]. Despite various challenges, there are several entry points where healthy ageing can be supported through the public-health framework [4], for example, supporting capacity-enhancing behavior for long-term care, removing 
barriers to participation and compensating for loss of capacity. Like many other countries, Australia has been facing significant challenges due to its ageing population. The State of Ageing in South Australia report states that population ageing is often seen as a negative phenomenon, which needs a cultural shift towards appreciating and capitalizing on the opportunities which ageing presents [5].

The issue of developing age-friendly communities arose from several policy initiatives launched by the World Health Organization (WHO) during the 1990s and early 2000s. A central theme concerned the idea of active ageing, originally developed during the United Nations' Year of Older People in 1999 [6]. The "active ageing" philosophy encourages us to optimize opportunities for health, participation and security to enhance people's quality of life as they age [7]. Related to this, the "age-friendly city" movement aims to ensure our urban environment is designed for and conductive to active ageing by involving older people in the assessment of a city's features [8]. The framework of sustainable development goals emphasizes the fulfilment of human potential with dignity and equality in a healthy environment regardless of age-group and race [9]. However, the built environment often excludes marginalized groups such as older people and others with special needs during planning and design considerations [10].

According to the WHO, an "age-friendly city" is an inclusive and accessible community environment that optimizes opportunities for health, participation and security for all people, in order that quality of life and dignity are ensured as people age [11]. The creation and maintenance of an age-friendly built environment is widely regarded as a core component of a positive approach to addressing the challenges of an ageing population As Bernard Isaacs, the founding director of the Birmingham Centre for Applied Gerontology reminds us, designing and building an age-friendly environment benefits all citizens, the old as well as the young. Therefore, research into age-friendliness should include gathering older people's opinions so that councils' policy formulation and decision making is directly informed by their ageing residents.

The WHO's age-friendly cities guidelines are global, and need to be integrated into local-level planning and development processes to promote age-friendly cities around the world [12]; however, age-friendly planning and development approaches are not simple and straight forward when it comes of implementing at local level. According to Buffel et al., three important factors such as political leadership, local narrative and partnership strategies need to be considered for the successful implementation of an age-friendly development [6]. Buffel et al., [12] also stated that much of the attention has shifted in recent years from questions such as "What is an ideal city for older people?" to the question of "How age-friendly are cities?" Identifying local priority indicators are important for the successful implementation of age-friendly development. This study considers the WHO's age-friendly checklist as the basis for implementing age-friendly development in Australia. In addition, the study considers the City of Unley a local government organization in South Australia as a case study. This study aims to identify the priority indicators of the age-friendly development for the City of Unley based on a perception survey and participatory community consultation process.

\subsection{Global Initiatives for Age-Friendly Cities}

To begin addressing ageing issues, the United Nations' General Assembly convened the first World Assembly on Ageing in 1982, which produced a 62-point Vienna International Plan of Action on ageing [13]. Twenty years later, the Second World Assembly on Ageing was held in Madrid with the aim of designing an international policy on ageing for the 21st century; it adopted a Political Declaration and the Madrid International Plan of Action on Ageing. The Plan of Action called for changes in attitudes, policies and practices at all levels to fulfil the potential of ageing in the 21st century [14].

In 2005, the World Health Organization and 33 of the world's cities collaboratively started the Global Age-friendly Cities project to provide "a universal standard for an age-friendly city" [12]. The age-friendly cities (AFC) checklist resulted from the WHO's collaborative project and consists of 88 "core-age-friendly features". It presents guidelines for urban age-friendliness in eight key areas: 
outdoor spaces and buildings, transportation, housing, social participation, respect and social inclusion, civic participation and employment, communication and information, and community support and health services [7]. Figure 1 shows the eight domains of the WHO's AFC checklist [8], which has provided the framework for this study.

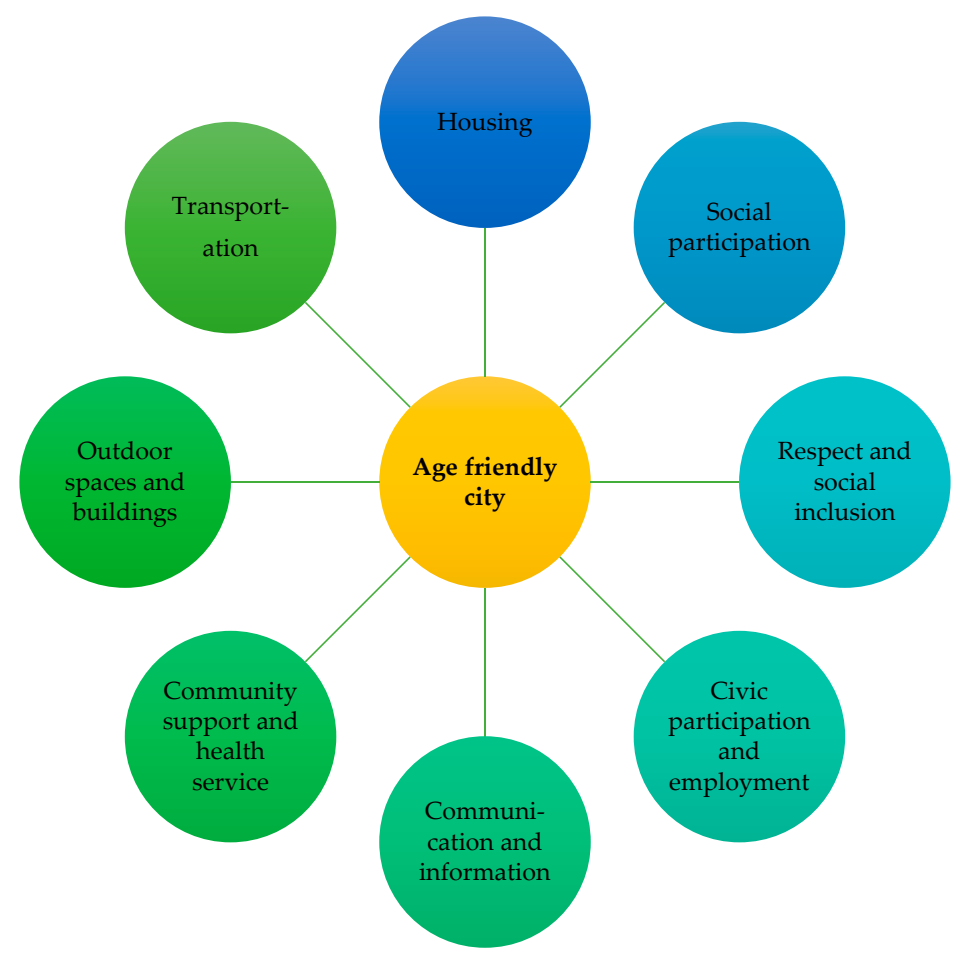

Figure 1. The key areas in WHO's age-friendly city guidelines [8] (WHO 2007a).

Following the inception of the WHO's age-friendly cities concept, the framework has been considered by many cities, countries and local communities around the world to create inclusive and accessible urban environments to benefit their ageing populations. To foster the AFC program, the Global Network of Age-friendly Cities and Communities (GNAFCC) has been established, where the members of the GNAFCC commit to following a five-year cyclic plan (see Figure 2) to work on these areas in a continuous process. The WHO's five-year cyclic plan for age-friendly cities has four stages: planning (years 1-2), implementation (years 3-5), evaluation (end of year 5) and improvement.

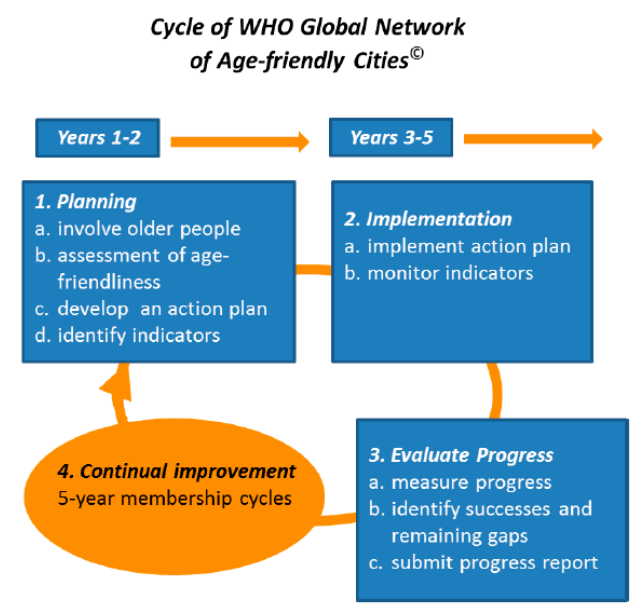

Figure 2. WHO Global Network of Age-friendly Cities planning framework [8]. 
Both the Madrid International Plan and the WHO's active ageing policy framework sit within the context of an international legal framework afforded by human rights law. They celebrate rising life expectancy and the potential of older populations to act as powerful resources for future development [4]. Several studies $[9,15]$ outlined that adaptation based on a locally tailored operational definition of the indicators of the international standing such as the WHO's AFC framework is necessary for successful implementation at local government or community level.

Previous community initiatives in the UK, the USA, Canada, Sub-Saharan Africa and other parts of the world have been implemented featuring various aspects of age-friendly development including physical infrastructure and social environment [9,16-18]. The City of Unley, a member of the GNAFCC since 2012, is required to implement such a plan. The WHO's collaboration with the world's cities and communities to develop their age-friendliness is now a part of the government of South Australia's age-friendly initiatives.

\subsection{Age-Friendly Initiatives in South Australia and the City of Unley}

South Australia's population is ageing more rapidly than other mainland Australian states. In 2011, around 34\% of South Australia's population were aged 50 years or over. By 2061, this proportion is expected to exceed $42 \%$ [19]. As there will be more than 440,000 people aged over 65, which is more than one in five of South Australia's total population [20] by 2031, South Australia has a special interest in developing age-friendly communities. The state government's Communities for All: Our Age-friendly Future is a response to South Australia's changing demographics and awareness that the environments and communities in which we live significantly influence our health and wellbeing. To this end, the South Australian government has produced three booklets containing age-friendly guidelines:

- Age-friendly Living: Guidelines for Residential Development which focuses on the physical environment and communities created in new greenfield and brownfield projects;

- Age-friendly Neighborhoods: Guidelines and Toolkit for Local Government which helps contribute to age-friendly communities-our urban and suburban areas and rural townships where we live, work and recreate; and

- Age-friendly South Australia: Guidelines for State Government which informs age-friendly policies, plans, programs and services.

The City of Unley is one of metropolitan Adelaide's local government areas. In 2016, the estimated residential population of the City of Unley was 38,916 people. Unley covers 1427 hectares $\left(14 \mathrm{~km}^{2}\right)$, making the population density approximately 27.28 persons per hectare [21]. The City of Unley has more dense housing ( $41 \%$ of its housing is medium or high density) than the South Australian average (24\%). In 2016, there were 15,402 households in Unley; the housing tenure was fully owned (33.3\%), mortgage (29.3\%), private rental (26.1\%), public housing (3.3\%) and other/not stated $(8 \%)$.

The ageing population (over 60 years) making up $25.3 \%$ of the population of Unley has increased significantly in recent years. Both the "young-old" and the "old-old" groups of Unley's population are growing, suggesting that Council services and programs need to be tailored for both these segments of the population. Looking at the ratio of older women to men in the Unley population, the number of women aged over 85 years old (1146) was over twice the number of men over 85 years old (490). There are 31 retirement villages in Unley. The only metropolitan Adelaide LGA with more retirement villages is the City of Norwood, Payneham, and St Peters (local suburbs of Unley), which have 35 aged care facilities [22]. There are nine suburbs in the City of Unley where over a third of the householders live alone [23]. These residents may be in aged care homes or they may need assistance that cannot be provided (unpaid) by a family member. According to 2016 census, around 1,431 females or $7.2 \%$ of the female population in the City of Unley, reported needing help in their day-to-day lives due to disability [21]. Therefore, an ageing population is one of the key concerns for local government. 
The City of Unley devised an Ageing Strategy for 2011-2014 that covers five areas: information and services, access and mobility, housing, community engagement and participation, and wellbeing [22].

\section{Materials and Methods}

The study applies a mixed methodology combining both quantitative and qualitative research methods. Figure 3 shows the key methodological approaches considered in the study. The research problems are formulated based on the knowledge gaps identified through a review of the relevant literature on age-friendly cities. The study considers the City of Unley as a case study area to conduct a community perception survey for measuring the age-friendliness and perform a community consultation on the priority indicators for the age-friendly cities.

A set of age-friendly indicators are assessed by residents of Unley who completed the survey questionnaire, either online or on paper. The questionnaire is designed by contextualizing the WHO's age-friendly cities (AFC) checklist of essential features to the situation in Unley. Several the WHO's checklist indicators were fragmented or merged or excluded while developing the survey list to improve the relevance and clarity of the indicators at local council level. For example, the number of sufficient public toilets and the accessibility of public toilets (ramps for disabled people) can be perceived differently, therefore, separate indicators were used in the questionnaire survey. After modification, a total of 81 indicators were used under 8 key areas for the perception survey to determine the age-friendliness of the areas based on participants' level of agreement and disagreement on the indicators for the City of Unley. The survey questionnaires used a five-point Likert Scale to rate each indicator from strongly disagree (1) to strongly agree (5) considering the relevance and age-friendless of the City of Unley. The hard-copy survey questionnaire was available to local people mainly at the local library, community hall and so on and administered by the local council. The online survey link was created so that local people could complete the survey via the Internet. The survey link was promoted and forwarded through the council's website. The survey was valid for any Unley resident of over 18 years of age. Since the survey was administered through the Council's website, Facebook and other electronic and social media (word of mouth), therefore, the response rate of the survey was not possible to measure.

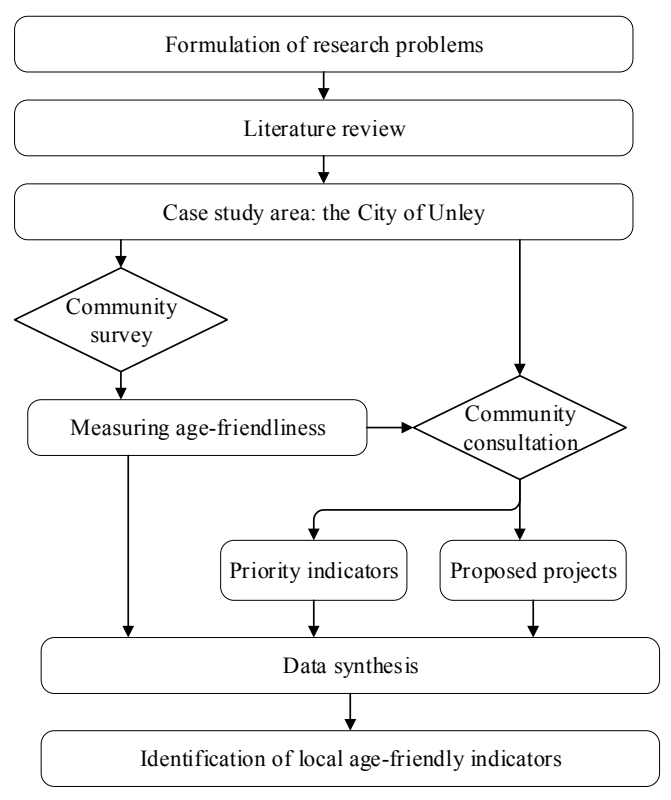

Figure 3. The key methodological approaches.

The City of Unley's age-friendliness was analyzed based on the mean value and the Relative Importance Index (RII) of each indicator used in the survey. The RII is a common technique to identify the most relevant and important indicators to the least relevant and important indicators from a set 
of questionnaire survey responses. The technique has been used for both agree/disagree and least important/most important type Likert scale questions [24-26]. The RII value indicates the level of satisfaction with or importance of each indicator. The RII of the 81 indicators in the City of Unley community questionnaire was measured using the equation below:

$$
\text { Relative Importance Index }(\mathrm{RII})=\sum \mathrm{w} / \mathrm{AN}
$$

where $\mathrm{w}$ is the weighting given to each factor by the respondent, ranging from 1 to 5 in which " 1 " is the lowest level of age-friendliness and " 5 " is the highest level of age-friendliness; A the highest weight, in this study $\mathrm{A}=5$; $\mathrm{N}$ the total number of samples; and RII, $0 \leq \mathrm{RII} \leq 1$.

$$
\mathrm{RII}=\text { Mean } / 5
$$

Three levels of age-friendliness: high (H) $(0.8 \leq \mathrm{RII} \leq 1)$, medium $(\mathrm{M})(0.5 \leq \mathrm{RII} \leq 0.8)$ and low (L) $(0 \leq \mathrm{RII} \leq 0.5)$, were then determined from the RII values. In the categorization of the age-friendliness from $\mathrm{L}, \mathrm{M}$ and $\mathrm{H}$, only the value less than the upper limit was considered, for example, less than 0.5 value were used in category $\mathrm{L}$ and 0.5 was included in the M category, similarly, 0.8 was included in the $\mathrm{H}$ category and not in the $\mathrm{M}$ category.

The findings of the questionnaire survey were presented to the focus group (mainly people over 60 years of age living at Unley). They were asked to prioritize the age friendly indicators based on local context. Since the key objectives of the second phase of study (community consultation) are to prioritize the important age-friendly cities indicators for the City of Unley and to conceptualize numbers of demonstration projects, thus, people over 60 (ageing population) who reside in the City of Unley were invited to participate in community consultation.

The public consultation was conducted by following a standard procedure such as notification to the public about the planned workshops, consultation to seek participants opinion and participation in the prioritizing of the indicators. The total number of participants for each group of consultation were limited to 15-20 participants for conducting an effective group discussion. A total of four public consultation workshops were conducted on different dates and times to maximize participation and a total of 52 participants attended the workshops. In addition, the participants were requested to propose age-friendly demonstration projects for the local community which would reflect the implementation of identified priority indicators at their locality. The workshop was moderated by the researchers using the specific guideline developed after the initial survey findings. The prioritization of the indicators was selected based on numbers of frequency in each workshop and qualitative analysis. The demonstration projects were also identified based on the frequency and the level of importance with local age-friendly development using a qualitative approach. The brainstorming sessions were conducted within each group to idealize the best fitting demonstration project and based on the available options, the most relevant and important demonstration project was identified based on public census. The study synthesizes the findings of the community survey and the priority indicators and the potential demonstration projects identified through a series of public consultations.

\section{Results}

The results section is divided into two sections to present the key findings of the questionnaire survey and community consultation sessions. It should provide a concise and precise description of the results, their interpretation as well as the conclusions that can be drawn.

\subsection{AFC Checklist Adapted for Unley Community Questionnaire}

The survey resulted in a checklist of 81 standards: 14 for Outdoor Spaces and Buildings, 12 for Housing, 21 for Transportation, 4 for Social Participation, 5 for Respect and Social Inclusion, 9 for Civic Participation and Employment, 6 for Communication and Information, and 10 for Community and Health Services. It is not clear from the WHO checklist specifically how one should determine whether 
the standards it presents as essential features of an age-friendly city are being met. They do, however, explain that "older people must be involved" in this determination [8]. The researchers decided that a survey which asks people to give their opinion using five-point Likert scale was a straightforward and effective way to provide an initial baseline about the City of Unley's age-friendliness. A synthesis of citizens' assessment of Unley's age-friendliness is given below.

\subsection{Participants' Background}

\subsubsection{Demographic and Health Status of the Participants}

A total of 195 residents living in the City of Unley participated in the Age-friendly Unley Community Consultation Survey. Of these, 68\% (134 persons) were female, and $32 \%$ were male (61 persons). People from various suburbs completed the survey including: Unley (20\%), Millswood (11\%), Fullarton (10\%), Parkside (9\%), Goodwood and Myrtle Bank (8\% each). Most respondents (97\%) were from non-Aboriginal or non-Torres Strait Islander backgrounds, only $1 \%$ were of Aboriginal and / or Torres Strait Islander background. Around 12\% (23 respondents) of the participants speak a language other than English at home, and 88\% (172 respondents) speak only English at home. Most of the respondents $(69 \%)$ were retired, $17 \%$ work part-time, $11 \%$ work full-time and $3 \%$ were unemployed. Regarding educational background, around $41 \%$ of the participants had a university or higher degree, $24 \%$ of the participants had a diploma or certificate, and $30 \%$ of the participants had a secondary school certificate.

Most respondents (72\%) stated their health was good or excellent, while $22 \%$ of the respondents reported fair health condition and the rest of $6 \%$ reported their health condition as poor. Around $31 \%$ of the participants (61 persons) have health problems that limit their ability to do daily activities, $66 \%$ of the participants were without any health problems when they completed the survey.

\subsubsection{Housing Ownership and Living Status}

Around $73 \%$ of respondents (as shown in Figure $4 a$ ) owned their home, $10 \%$ were renting privately, $11 \%$ had a mortgage, and only $4 \%$ rented publicly provided housing. Around $38 \%$ respondents (79 persons) live alone in their home, $47 \%$ of respondents live with their spouse or partner, $10 \%$ of respondents had their children living with them, 3\% respondents live with other relatives and only $3 \%$ respondents shared their home with a non-relative (as shown in Figure $4 b$ ).

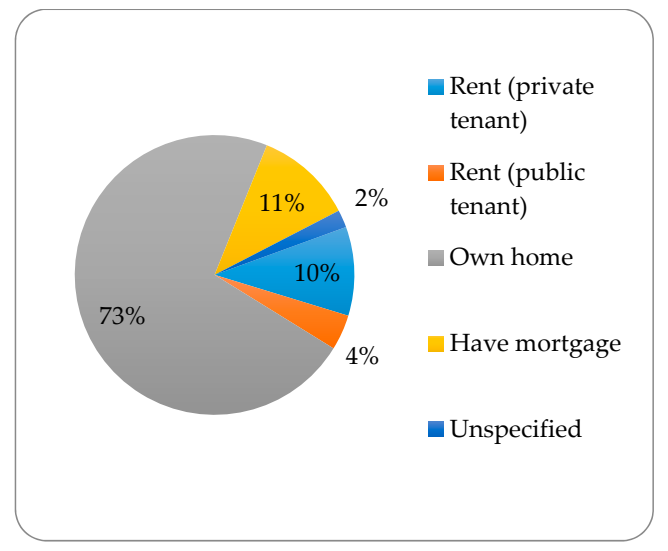

(a)

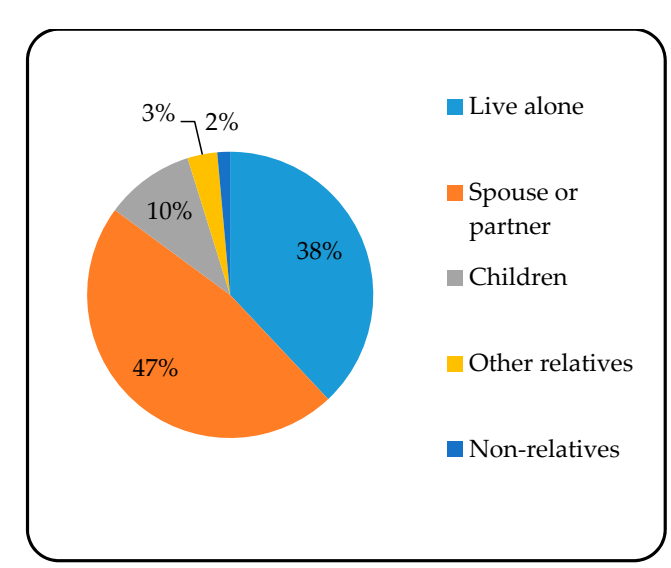

(b)

Figure 4. Participants' ownership of the housing (a) and living status (b).

\subsection{Community Perception Survey Results}

As described, participants' score (1-5) each indicator in the questionnaire based on the level of importance regarding age-friendly development at the City of Unley. In the domain of Outdoor 
Spaces and Buildings, recreational facilities could cater more for older people; although $50 \%$ of the respondents agreed that they did so, 20\% disagreed and 30\% were undecided. Older people's most common form of physical recreation is going for a walk and while $65 \%$ of respondents agreed that Unley's footpaths are clear, $46 \%$ of respondents thought they are not wide enough for wheelchairs. Turning to street lighting, only $49 \%$ of respondents agreed that Unley's streets are well lit, over a third disagreed. Similarly, $48 \%$ of respondents agreed that there are enough public toilets, and $30 \%$ disagreed. Overall, however, most respondents agreed that there is sufficient seating, public buildings are well signed and accessible, and pedestrian crossings are convenient and safe to use. Respondents' comments included "trees are important" and a call for "more open green space and shade trees".

The Transportation domain covers standards of public transport, community transport, road maintenance, signage, driving and parking. While problems with public transport are outside local government responsibilities, responses suggest that the provision of information about the availability of community transport and specialized transport services for people with disabilities could be improved. Most respondents agreed that roads are well maintained and clearly signed, and that adequate parking spaces are available, but over a third disagreed that the amount of priority/disabled parking spaces is adequate. The most significant result was in response to the availability of driving education for older people: $72 \%$ of respondents indicated that it was not available, suggesting that there is a need for education that Council could facilitate via courses at community centers and/or making training available online via the library website. Traditionally, the main involvement of local government with Housing is "planning for land use and regulating development"; there may be an increasing role in negotiating the co-location of aged care homes, retirement villages or residential development aimed at older people with facilities and services [27]. The Housing standards that respondents evaluated included assistance with home maintenance, over a third agreed that they required help with gardening or cleaning. The vast majority of respondents want to stay in their current home for as long as possible. If they must move, only $39 \%$ think that they could downsize easily, only $30 \%$ think that houses in Unley are suitably designed for older people and only $21 \%$ think that they could find a suitable alternative home in Unley. This suggests a role for Council in both the provision of information and the encouragement of suitable residential design and development. The purpose of the standards in the Social Participation domain is to ensure "consistent outreach to include people at risk of social isolation" [8]. While $68 \%$ of the respondents said they participate in social activities outside their homes, $22 \%$ do not and $10 \%$ did not give a relevant answer. Given that only $47 \%$ of respondents agreed that local events are inclusive of older people and that a third of respondents thought local venues were neither easy to access nor affordable, there is room for improvement. Respondents commented that social participation often relies on access to a private car and adequate parking, and that what will appeal to someone in their 60s differs from what appeals to someone in their 80s. Here, we see the difference between the "young-old" and the "old-old". Participants stated that " ... children should be advised to stand for elderly, disabled or pregnant people."

The Relative Importance Index (RII) were calculated to identify the important indicators to comparatively low importance indicators based on community perceptions. Table 1 shows the summarized finding of the survey findings of the questionnaire survey.

Table 1. Mean value, Relative Importance Index of age-friendly city indicators.

\begin{tabular}{|c|c|c|c|c|}
\hline Domain & Indicator & Mean & RII & $\begin{array}{c}\text { Performance } \\
\text { Level }\end{array}$ \\
\hline & (a) Public areas are clean and well-maintained & 3.97 & 0.80 & $\mathrm{H}$ \\
\hline & (b) There is sufficient green space & 3.48 & 0.69 & $\mathrm{M}$ \\
\hline & (c) Recreation facilities cater for older people & 2.98 & 0.59 & M \\
\hline 1. Outdoor & (d) Footpaths are free from obstructions or hazards & 2.96 & 0.59 & M \\
\hline Spaces and & (e) Footpaths are wide enough to accommodate wheelchairs/mobility scooters & 2.85 & 0.57 & M \\
\hline \multirow[t]{4}{*}{ Buildings } & (f) Pedestrian crossings are conveniently located & 3.31 & 0.66 & M \\
\hline & (g) Pedestrian crossings allow sufficient time to cross the road safely & 3.50 & 0.70 & M \\
\hline & (h) Streets are well-lit at night & 3.12 & 0.63 & M \\
\hline & (i) Public buildings are easy to access & 3.61 & 0.72 & M \\
\hline
\end{tabular}


Table 1. Cont.

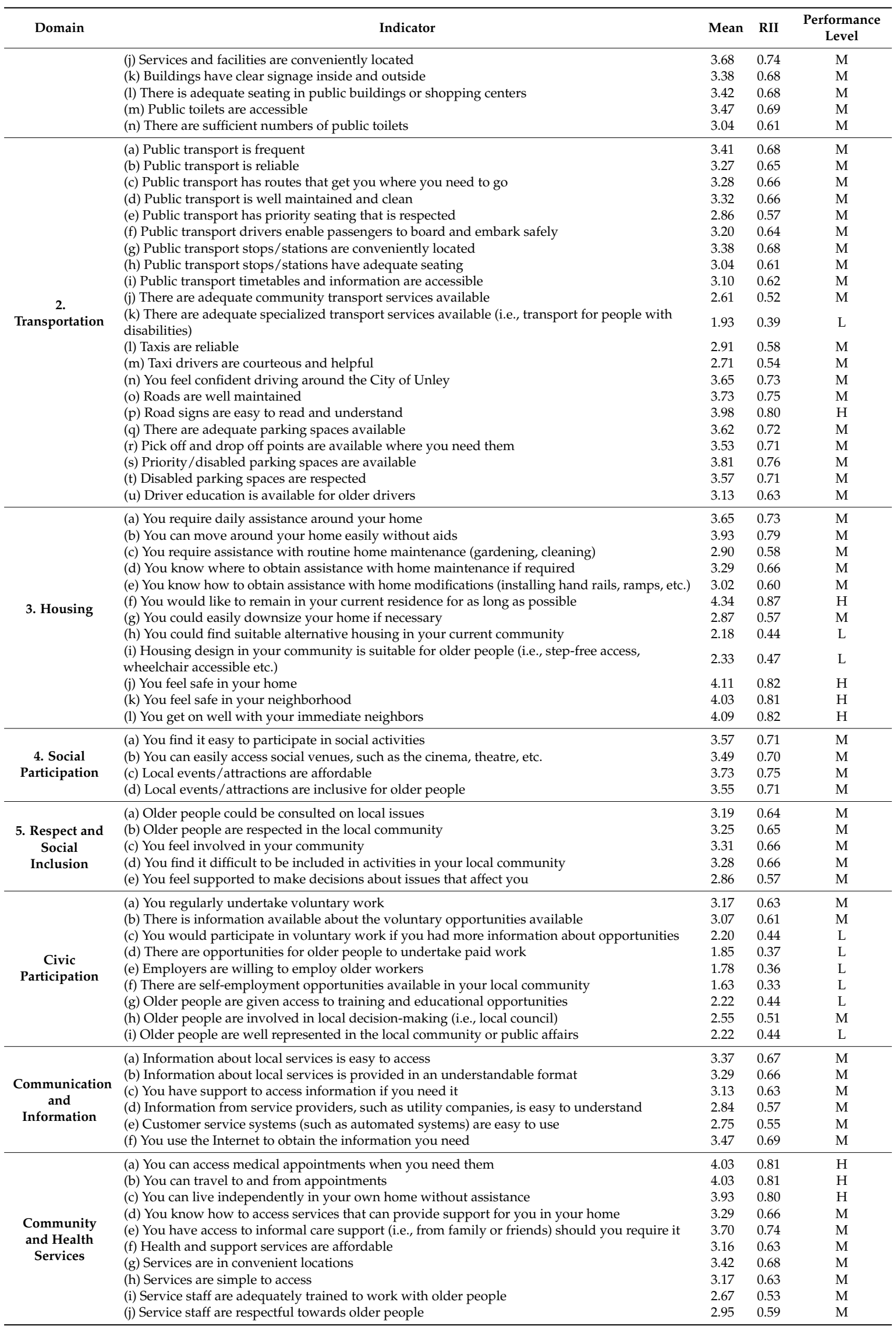


Regarding age-friendliness analysis, the study indicates that the City of Unley is performing relatively well in several areas such as outdoor space, transportation, social participation, community health service areas; however, several areas such as civic participation and housing need more attention to transform Unley into a truly age-friendly city.

\subsection{The Key Priority Indicators for the City of Unley}

Of the 81 indicators assessed by the respondents, nine indicators have a high RII, nine indicators have a low RII and the remaining 63 are medium (within this large group of "adequate" performers, the 12 at the bottom end of that scale are worth noting). From this it is clear that the 195 residents who completed the questionnaire think that the City of Unley has both strengths and weaknesses in the eight domains of age-friendliness. Some of the indicators evaluated by the RII ranking, such as taxi drivers' courtesy, information from utility companies or employers' willingness to employ older workers, are not traditionally the responsibility of local government. However, the City of Unley could, if it wished to do so, help by "being the change" necessary to encourage our society's shift towards greater age-friendliness, via local public information and education campaigns or setting an example in its hiring practices. Other indicators, such as providing age-friendly recreation facilities, ensuring that footpaths are clear and smooth, and involving older citizens and their representatives in local decision-making processes, are clearly local government matters.

Several participatory community consultation sessions were conducted (as shown in Figure 5) with local residents to identify the priority indicators for the City of Unley. Based on the findings of the public consultations, around 25 indicators were identified as the priority indicators to foster age-friendly development in the locality. Table 2 lists these indicators, which Unley Council could incorporate into its next age-friendly strategy.
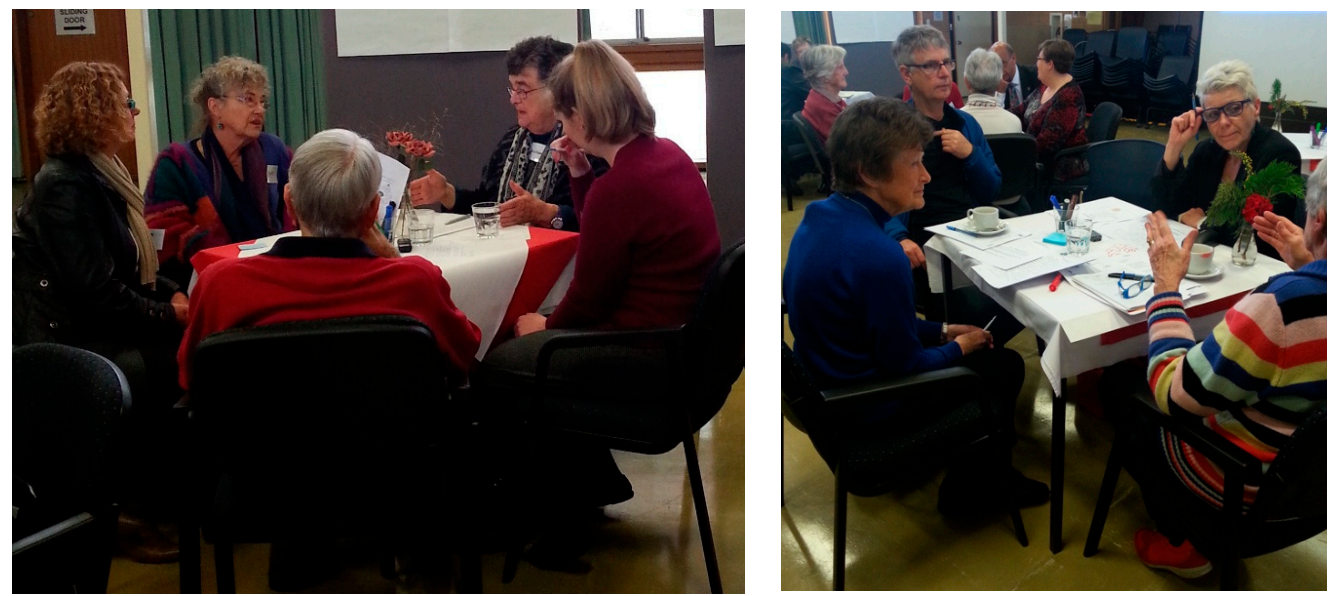

Figure 5. Unley residents at community consultation about age-friendliness.

In the Outdoor Spaces and Buildings domain, the indicators recognize the importance of well-maintained footpaths and outdoor spaces. There is a special emphasis on access to recreation in the natural environment, as the latest research in urban planning identifies nature as essential for wellbeing. One participant during the public consultation said that "Unley has wonderful outdoor spaces and lovely old buildings."

The Transportation domain indicators highlight signage and parking and suggest community transport be broadened to include specialized transport services (this is an opportunity for the "young-old" to be part of a voluntary service). To avoid the inference that it is only older people who need to brush up their skills, the final indicator recommends driver education for adults of all age. Although driver education is not usually a local government responsibility, the strength of responses to 
this indicator suggests that Unley residents would appreciate more information about it. A participant stated during the workshop that "the community bus around Unley is great".

The questionnaire identified that respondents feel safe and comfortable in their home, get on with their neighbors and wish to stay in their current home for as long as they can, hence, the Housing domain's indicators are about information and assistance with routine home maintenance and modification. They also acknowledge respondents' concern that it would be difficult for them to downsize their home or to find suitable alternative housing in their community by prioritizing these indicators.

Indicators in both the Social Participation and the Respect and Social Inclusion domains generally received a medium performance level rating from respondents. Therefore, the indicators in the Social Participation domain highlight access to local venues and events, while the Respect and Social Inclusion indicators emphasize older citizens being consulted about local issues and supported to make decisions about issues that affect them.

Table 2. Identified priority indicators of age friendly development at the City of Unley.

\begin{tabular}{|c|c|}
\hline $\begin{array}{l}\text { Domain } \\
\text { (Number of Indicators) }\end{array}$ & Priority Indicators for the City of Unley \\
\hline \multirow[b]{2}{*}{$\begin{array}{l}\text { Outdoor Spaces and } \\
\text { Buildings (4) }\end{array}$} & Local public areas are clean, pleasant and well-maintained. \\
\hline & $\begin{array}{l}\text { There are sufficient local open green spaces, with adequate seating and suitable pathways, } \\
\text { for people to access and enjoy being with nature. }\end{array}$ \\
\hline \multirow[b]{3}{*}{ Transportation (4) } & Road signs are easy to read and understand. \\
\hline & Adequate and convenient parking, including priority/disabled, spaces are available. \\
\hline & $\begin{array}{l}\text { Adequate local community transport services, including specialized services for people with disabilities, } \\
\text { are available. }\end{array}$ \\
\hline \multirow[t]{3}{*}{ Housing (4) } & $\begin{array}{l}\text { Residential building regulations allow homes to be easily downsized if necessary and information about } \\
\text { how to do so is available. }\end{array}$ \\
\hline & Older people feel safe, secure and comfortable in their homes. \\
\hline & $\begin{array}{l}\text { Housing designed to suit older people (i.e., step-free access, wheelchair accessible, etc.) } \\
\text { is locally available. }\end{array}$ \\
\hline \multirow{2}{*}{ Social Participation (2) } & Older people can easily access local social venues, such as the cinema, theatre, etc. \\
\hline & Local events are inclusive of older people. \\
\hline \multirow{2}{*}{$\begin{array}{l}\text { Respect and Social } \\
\text { Inclusion (2) }\end{array}$} & Older people are consulted about local issues. \\
\hline & Older people feel supported to make decisions about issues that affect them. \\
\hline \multirow{2}{*}{$\begin{array}{l}\text { Communication and } \\
\text { Information (3) }\end{array}$} & Council customer service systems (such as automated systems) are easy to use. \\
\hline & $\begin{array}{l}\text { Local libraries provide older people with access to and assistance in understanding } \\
\text { important information. }\end{array}$ \\
\hline \multirow{2}{*}{$\begin{array}{l}\text { Community and } \\
\text { Health Services (2) }\end{array}$} & Older people know how to access in-home care and support services. \\
\hline & $\begin{array}{l}\text { Council staff and those employed in delivering council services are trained to work respectfully with } \\
\text { older people. }\end{array}$ \\
\hline
\end{tabular}

Seven of the nine indicators for Civic Participation and Employment received a low performance rating from respondents. Therefore, the four key indicators proposed here respond to the needs identified for information about local opportunities for older people's training, education, 
self-employment, voluntary and paid work, the involvement of older people in local decision-making, and their representation in local matters.

The Communication and Information's six indicators all received an adequate (medium) performance level rating. However, these ratings were at the low end of medium for how easy automated systems are to use and how easy information from service providers (utilities) is to understand. Therefore, two of the three indicators proposed encourage Council to ensure that their information is clearly presented and easy to use. The third indicator recognizes the essential role of local libraries as a helpful source of information. This was confirmed by the community consultation [28].

The Community and Health Services indicators generally rated high or medium, which suggests that the respondents think the health and community care services in the City of Unley are of a good standard. Worth noting, however, are the low end of medium ratings for the two indicators about service staff, this implies that more training about the needs of older clients and some education in the philosophy of positive ageing would be appropriate. That is why the two key indicators proposed for this domain promote relevant training in age-friendliness for Council staff and service providers and the provision of information about in-home care and support.

The 25 key indicators proposed here are a balance between things that the City of Unley is already doing well, things it could improve and a limited selection of new areas where it could reasonably hope to engage and make a difference. The projects suggested for the "Unley Central" precinct, discussed in the next section, also offer ways for the City of Unley to design and embed age-friendly features and standards in the local community.

\section{Discussion and Possible Demonstration Projects for the Age-Friendly Development}

As a member of the WHO's Global Age-friendly Network, the City of Unley is following a five-year cyclic plan that involves planning, implementing, evaluating and continuously improving its age-friendliness. The community consultations were also emphasized on identifying potential demonstration projects for the local community, so that the identified priority indicators can be considered for the Unley Central Redevelopment Project. The redevelopment project would be an opportunity to apply and implement the identified age-friendly demonstration projects from the consultation workshops. To find and idealize the demonstration projects, the key emphasis was given on how the proposed projects were highly relevant to the priority indicators. Walkability has been identified as one of the key features of the age-friendly development, especially at Unley Central and Figure 6 shows the proposed development plan of the Unley Central's District Centre Zone to improve the walkability.

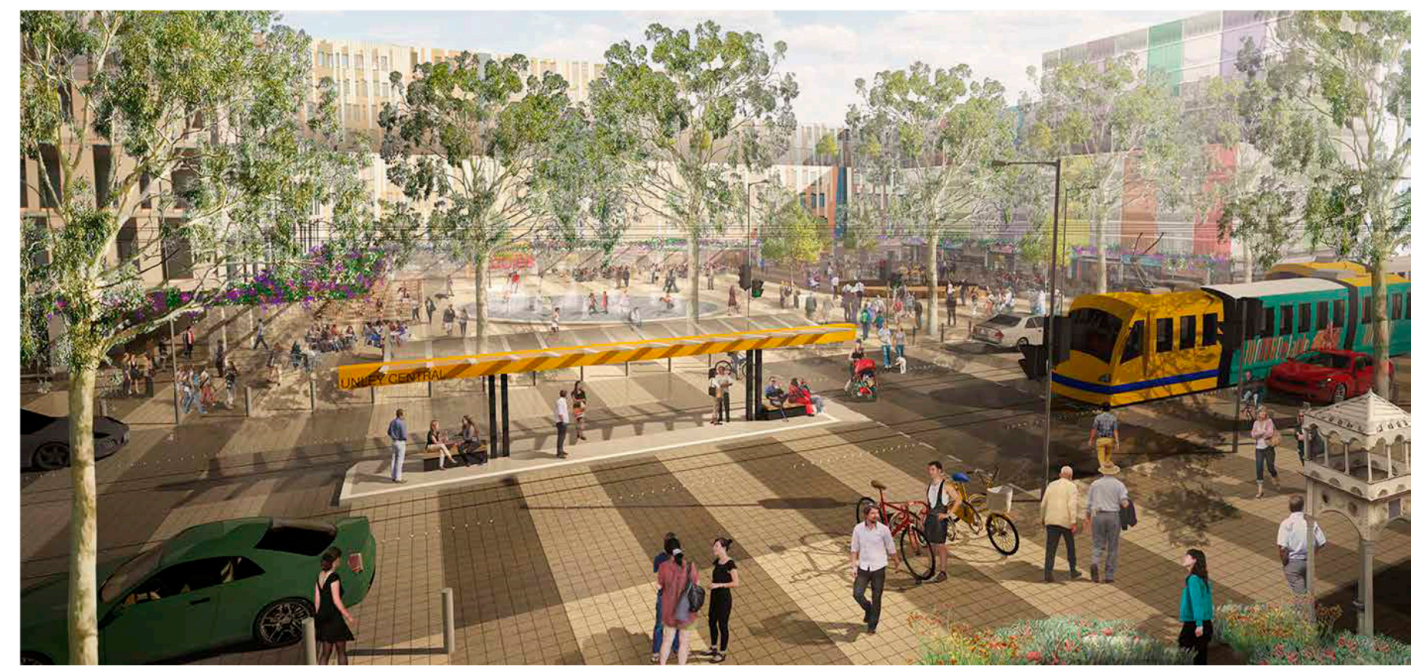

Figure 6. Depiction of Unley Central's District Centre Zone, looking East across Unley Road [29]. 
While the age-friendliness of the Unley Central precinct as a whole will be underlined by calming traffic and enhancing walkability, based on the community consultation, the researchers propose four specific projects that could be sited within the precinct to showcase age-friendly features in respect to safe and affordable housing, intergenerational inclusive and connected society, responsible community fostering sustainable waste management, and circular economy. A brief description and benefits of the potential projects are given below.

\subsection{Social Co-Housing}

The concept of co-housing has been accepted around the world as it creates enriched communities, enhances sharing and promotes sustainability by providing common facilities such as open space, courtyards, a playground and gardens (www.cohousing.org). Unley has a significant number of retirement villages that offer a similar service for ageing people. The City of Unley could support and approve the development of age-friendly co-housing projects by encouraging the creation of step-free and/or wheelchair accessible homes.

A co-housing project (example shows in Figure 7) would accommodate people in various age-groups who wish to live somewhere with shared facilities. Ideally, this would allow residents to get to know each other, something that traditional single household dwelling can inhibit. Co-housing would facilitate social interaction among neighbors, which has intangible and practical advantages. It could be a multi-story residential development that uses universal design principles sited within the Unley Central precinct.
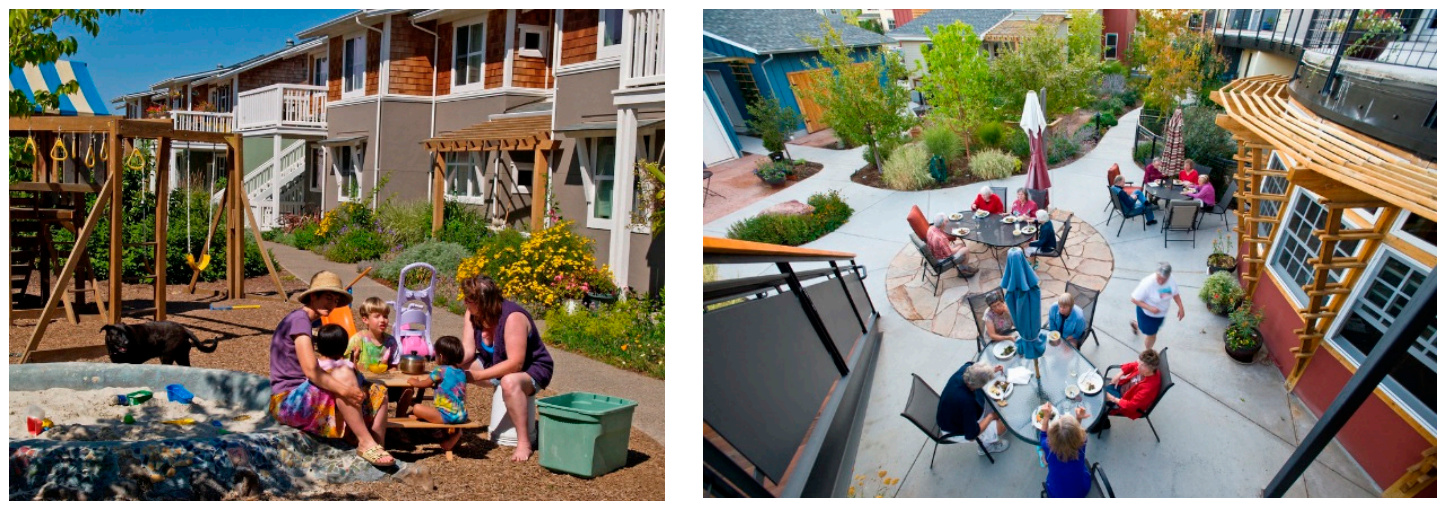

Figure 7. Co-housing project in the USA [30].

One respondent called for "more effort in community village creation for residents who want to downsize and stay in the area and are not yet ready for care facilities". Several focus group member emphasize that the intergenerational co-housing model would significantly address their current challenges in relation to social inclusion and building social safety net. The co-housing model not only provides the opportunity of downsizing or sharing the land area with intergenerational co-residences but also allow them to interact with people and feel safe, which eventually improves overall wellbeing.

\subsection{Unley Centre of Age-Friendly Excellence (UCAE)}

The Unley Centre of Age-friendly Excellence (UCAE) project would provide information about innovations and best practices in age-friendly development around the world. It would build on the City of Unley's membership of the WHO's Global Network of Age-friendly Cities and Communities. The UCAE is a response to the feedback received from the community consultation for this study that indicates many older residents are unaware of courses that might interest them, are unsure that older people's opinions inform local decision-making and/or that staff are trained to work with older people. Communication and information sharing with local residents is one of the key priorities of local government to ensure an effective representation of the community and the public participation 
in the development process. It is often evident that local councils predominantly rely on the electronic media as a main source of communication channel. One participant stated that "there is a tendency to think that everything can be done online these days. An old-fashioned letterbox drop may be better to include all people", the statement indicates that the UCAE needs to focus on both electronic and traditional channels of communication. The UCAE's management and direction should be co-created by Unley Council and representatives of local older citizens and the agencies working with them. Key priorities of the UCAE would be to:

- $\quad$ share knowledge about best-practice age-friendly strategies, policies and programs;

- organize workshops and other opportunities to gather community input on age-friendly developments in Unley;

- provide training for older people on the latest technologies (such as smart phones, mobile apps and internet platforms) and education such as refresher courses for older drivers or how to downsize one's home or interpret bills from utility providers;

- provide education and training in the philosophy of positive ageing and age-friendliness for businesses, government and non-government organizations that service older people;

- $\quad$ establish WAP-points (wireless access points) or Wi-Fi hotspots for residents to use their gadgets and access the Internet; and

- create mobile apps to provide information about services, businesses, and volunteering opportunities for older residents.

\subsection{Silver Garden}

The Silver Garden would be a community garden for older residents and their collaborators. There are over 50 community gardens in South Australia, not least the well-known and long-running Fern Avenue garden in Unley (see Figure 8). People can improve both their physical and mental health by being part of a community garden. In addition, it can provide intergenerational interaction and improve people's sense of connection to their community and local environment.

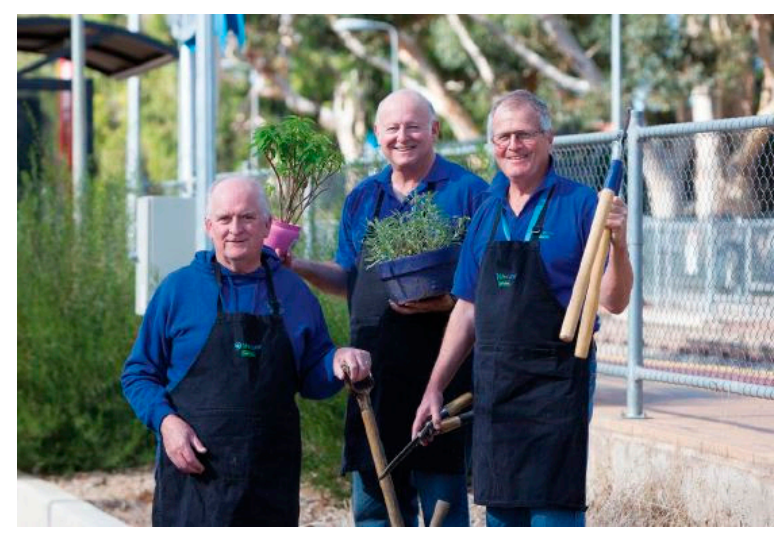

Figure 8. Unley gardening volunteers [23].

The regeneration of the Unley Centre Community Garden as a kitchen garden that provides produce for the community center and the creation of a vertical garden at the Clarence Park Community Centre both show that there is a strong interest in and enthusiasm for more Council-supported productive gardens in Unley. One of the respondents recommended "more community produce/veggie gardens" as one of the things that could make Unley a better place to grow old. A community garden that included age-friendly elements in its design, such as smooth, wide paths (for access by people using walking frames or wheelchairs) and raised beds (reducing the need to kneel and again allowing access by people in wheelchairs) would allow older residents to continue to reap the benefits (pun intended!) of gardening. 
The Silver Garden is also an opportunity to make Unley Central more sustainable and inspirational by making its landscape design productive as well as visually appealing. Residents could reduce their food bills by growing their own fresh produce. Excess produce could be traded in the "village shop".

\subsection{Co-Operative Social Business}

The Unley community business project would be based on social enterprise principles. The social business model is a non-loss, non-dividend co-operative venture that operates as a for-profit organization to generate social capital. The Unley community business project would be useful to create opportunities for and provide services to the local community. It could start as a community-operated shop where locally grown foods (including produce from the Silver Garden) or locally made products were traded. The shop would run and be staffed by local retirees or older people. The shop would provide opportunities for older people to gain new skills and/or make use of the skills they acquired during their "pre-retirement" lives and create income opportunities for the ageing people which is one of least performing areas of age-friendliness of the City of Unley (see Table 1).

The community-owned "village shop" movement is gathering momentum in the UK (as shown in Figure 9) and a new report highlights their growth and resilience [31]. The report states that "community-owned village shops continue to be one of the leading success stories of the UK co-operative and community enterprise movement. In 1993 there were just 23 community-owned shops trading in the UK; 20 years on there are 303, with a further 30 anticipated to open in 2013." A co-operatively owned and operated shop could be part of a retail experience that is unique to Unley Central, enhancing its desirable village character and atmosphere with a genuine "village shop". In addition, cooperative business will allow ageing persons to meet local people and create a socially inclusive atmosphere to enhance the belongingness to the locality despite being "old".

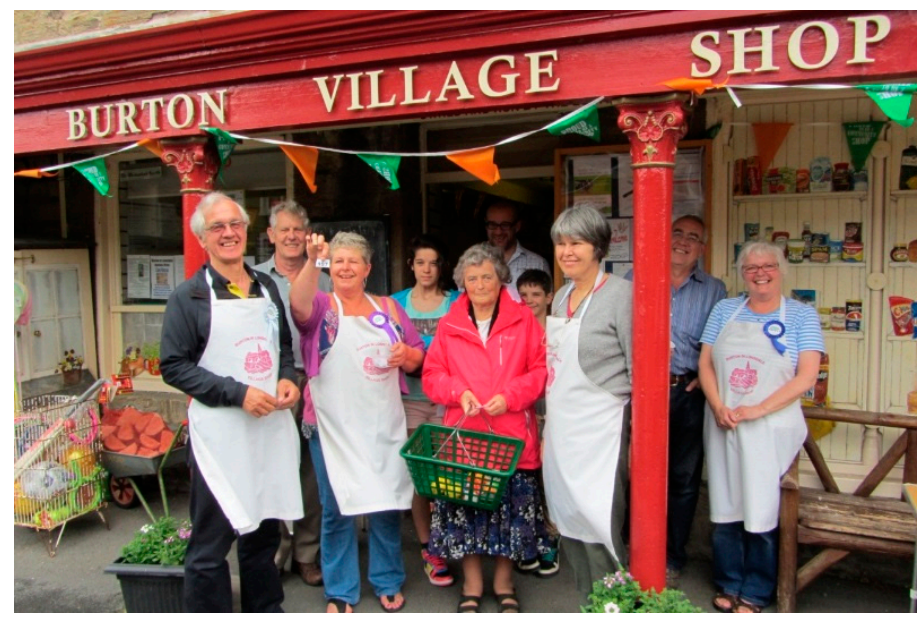

Figure 9. Community-owned village shop in Burton-on-Trent, Staffordshire, England [31].

\section{Conclusions}

The is no denial that the life expectancy as well as the proportion of ageing population will grow more in the future due to economic growth and the advancement of healthcare technologies. We need to prioritize our development strategy to address the emerging ageing challenges that many countries are currently facing today. The WHO's Global Age-Friendly Cities serves as a reference for communities to assess their age-friendliness and to plan for the necessary changes.

This study used the WHO's checklist to analyze the current state of age-friendliness of the City of Unley in South Australia. The study indicated that the City of Unley is performing well in several areas such as outdoor space, transportation, social participation, community health service areas; however, several areas such a civic participation and housing need more attention to make Unley an 
age-friendly city. The study identified 25 key priority indicators which need to be considered to plan for age-friendly communities at Unley. The demonstration projects were proposed by local people assuming that the priority indicators would be reflected through similar real-life projects in their local community.

The authors acknowledge that the findings of the study could be interpreted differently if a different methodological approach were employed. However, the key objectives of the study are to assess the age-friendliness of the City of Unley and identify the priority areas for future development through several demonstration projects proposed by local residents. Despite recognizing the limitation of the study, the authors strongly believe that the findings of the study would be helpful in developing local age-friendly development strategy for the local council. Since the study is based on a participatory community consultation process, community expectations are assumed to reflect through the findings of the study.

Author Contributions: A.Z. conceived project idea, designed the public consultation and conducted the survey and data collection. A.Z. and K.T. analyzed the data and wrote the article.

Funding: This research was funded by the City of Unley, grant number 8/2014.

Acknowledgments: This article is extracted from the project on "Age-friendly City Standards: The City of Unley" a joint project between the University of South Australia and the City of Unley. The authors thank the City of Unley for supporting the project. The Authors would like to thank two anonymous reviewers for their valuable suggestions to improve the manuscript.

Conflicts of Interest: The authors declare no conflict of interest.

\section{References}

1. United Nations Department of Economic and Social Affairs (UN-DESA). World Population Prospects: The 2017 Revision. Available online: http:/ / esa.un.org/unpd/wpp/index.htm (accessed on 25 July 2017).

2. Global Age Watch Index (GAWI). Life Expectancy at 60. 2013. Available online: http:/ / www.helpage.org/ global-agewatch/data/life-expectancy-at-60/ (accessed on 25 July 2017).

3. OECD. Health at a Glance 2013: OECD Indicators; OECD Publishing, 2013. Available online: http://dx.doi. org/10.1787/health_glance-2013-en (accessed on 12 September 2017).

4. WHO. World Report on Ageing and Health; World Health Organization: Geneva, Switzerland, 2015. Available online: http://apps.who.int/iris/bitstream/handle/10665/186463/9789240694811_eng.pdf? sequence $=1$ (accessed on 1 June 2018).

5. Hugo, G.; Luszcz, M.; Carson, E.; Hinsliff, J.; Edwards, P.; Barton, P.; King, P. State of Ageing in South Australia; Department for Families and Communities, Government of South Australia: Adelaide, SA, Australia, 2009.

6. Buffel, T.; McGarry, P.; Phillipson, C.; De Donder, L.; Dury, S.; De Witte, N.; Verté, D. Developing Age-Friendly Cities: Case Studies from Brussels and Manchester and Implications for Policy and Practice; Environmental Gerontology in Europe and Latin America; Springer: Cham, Switzerland, 2016; pp. 277-296.

7. World Health Organization (WHO). Global Age-Friendly Cities: A Guide; World Health Organization: Kobe, Japan, 2007. Available online: http://www.who.int/ageing/publications/Global_age_friendly_cities_ Guide_English.pdf (accessed on 25 July 2017).

8. World Health Organization (WHO). Checklist of Essential Features of Age-Friendly Cities. 2007. Available online: http://www.who.int/ageing/publications/Age_friendly_cities_checklist.pdf?ua=1 (accessed on 25 July 2017).

9. Aboderin, I.; Kano, M.; Owii, H.A. Toward "Age-Friendly Slums"? Health Challenges of Older Slum Dwellers in Nairobi and the Applicability of the Age-Friendly City Approach. Int. J. Environ. Res. Public Health 2017, 14, 1259. [CrossRef] [PubMed]

10. Scott, I. Mobility, Mood and Place-Co-Designing Age-Friendly Cities: A Report on Collaborations between Older People and Students of Architecture. Arts 2017, 6, 12. [CrossRef]

11. WHO. Measuring the Age-Friendliness of Cities: A Guide to Using Core Indicators; World Health Organization: Kobe, Japan, 2015; ISBN 978-92-4-150969-5. Available online: http:/ /apps.who.int/iris/bitstream/handle/ 10665/203830/9789241509695_eng.pdf;jsessionid=1ED83ADFF9F18BDBA1CCC4F677D53245? sequence=1 (accessed on 12 September 2017). 
12. Plouffe, L.; Kalache, A. Towards global age-friendly cities: Determining urban features that promote active aging. J. Urban Health 2010, 87, 733-739. [CrossRef] [PubMed]

13. Buffel, T.; Phillipson, C.; Scharf, T. Ageing in urban environments: Developing 'age-friendly' cities. Crit. Soc. Policy 2012, 32, 597-617. [CrossRef]

14. United Nations (UN). Ageing. 2013. Available online: http://www.un.org/en/globalissues/ageing/ (accessed on 25 July 2016).

15. Plouffe, L.A.; Kalache, A. Making communities age friendly: State and municipal initiatives in Canada and other countries. Gaceta Sanitaria 2011, 25, 131-137. [CrossRef] [PubMed]

16. Lui, C.W.; Everingham, J.A.; Warburton, J.; Cuthill, M.; Bartlett, H. What makes a community age-friendly: A review of international literature? Australas. J. Ageing 2009, 28, 116-121. [CrossRef] [PubMed]

17. Fitzgerald, K.G.; Caro, F.G. An overview of age-friendly cities and communities around the world. J. Aging Soc. Policy 2014, 26, 1-18. [CrossRef] [PubMed]

18. Greenfield, E.A.; Oberlink, M.; Scharlach, A.E.; Neal, M.B.; Stafford, P.B. Age-friendly community initiatives: Conceptual issues and key questions. Gerontologist 2015, 55, 191-198. [CrossRef] [PubMed]

19. SA Health. Age Friendly SA: A Great Place to Spend a Lifetime. 2018. Available online: http:/ / www.sahealth.sa.gov.au/wps/wcm/connect/Public+Content/SA+health+Internet/About+ us/Department+of+Health/Office+for+the+Ageing/Age+Friendly+SA (accessed on 7 May 2018).

20. Government of South Australia (GSA). South Australia's Communities for All: Our Age-Friendly Future; Government of South Australia: Adelaide, SA, Australia, 2012. Available online: http:/ / agefriendlyworld. org/en/wp-content/uploads/2014/05/south-australia-guide.pdf (accessed on 2 February 2015).

21. Profile.ID. City of Unley: Community Profile. 2018. Available online: https://profile.id.com.au/unley (accessed on 20 February 2018).

22. City of Unley (CoU). Unley Ageing Strategy; 2011. Available online: http://www.unley.sa.gov.au/webdata/ resources/files/Unley\%20Ageing\%20Strategy.pdf (accessed on 20 June 2016).

23. Suter Planners n.d. City of Unley Community Profile. Available online: http:/ /www.unley.sa.gov.au/webdata/ resources/files/3428_CommunityProfile_WEB.pdf (accessed on 1 March 2017).

24. Aziz, N.; Zain, Z.; Mafuzi, R.M.Z.R.; Mustapa, A.M.; Najib, N.H.M.; Lah, N.F.N. Relative Importance Index (RII) in Ranking of Procrastination Factors among University Students; AIP Publishing: Melville, NY, USA, 2016; Volume 1761, p. 020022.

25. Durdyev, S.; Zavadskas, E.K.; Thurnell, D.; Banaitis, A.; Ihtiyar, A. Sustainable Construction Industry in Cambodia: Awareness, Drivers and Barriers. Sustainability 2018, 10, 392. [CrossRef]

26. Muhwezi, L.; Acai, J.; Otim, G. An assessment of the factors causing delays on building construction projects in Uganda. Int. J. Constr. Eng. Manag. 2014, 3, 13-23.

27. O'Brien, E.; Phibbs, P. Local Government and Ageing: Literature Review; Urban Research Centre, University of Western Sydney \& Department of Families and Community Services, NSW Government: 2011. Available online: https:/ / www.adhc.nsw.gov.au /_data/assets / file/0004/250825/21_OBrien_and_Phibbs_ 2011_Local_Govt_Ageing_Literature_Review.pdf (accessed on 28 February 2015).

28. O'Hehir, J. Age-Friendly Cities: Unley Consultation Report; Unpublished Manuscript; University of South Australia: Adelaide, SA, Australia, 2014.

29. Taylor Cullity Lethlean. Unley Central Precinct Study [Draft]. 2014. Available online: http:/ / www.unley. sa.gov.au/webdata/resources / files / Att\%201\%20Item\%201221\%20FCM\%2011\%20August\%202014.pdf (accessed on 2 February 2015).

30. McCamant \& Durrett Architects. The Cohousing. 2016. Available online: http://www.cohousingco.com/ blog/ (accessed on 12 June 2017).

31. Plunkett Foundation. A Better Form of Business: Community-Owned Village Shops. 2013. Available online: http:/ / www.plunkett.co.uk/templates/asset-relay.cfm?frmAssetFileID=1633 (accessed on 2 February 2015).

(C) 2018 by the authors. Licensee MDPI, Basel, Switzerland. This article is an open access article distributed under the terms and conditions of the Creative Commons Attribution (CC BY) license (http://creativecommons.org/licenses/by/4.0/). 